\title{
Alternative splicing of AMPA subunits in prefrontal cortical fields of cynomolgus monkeys following chronic ethanol self-administration
}

\author{
Glen Acosta ${ }^{1}$, David P. Freidman ${ }^{1}$, Kathleen A. Grant ${ }^{2}$ and Scott E. Hemby ${ }^{1,3}$ * \\ 1 Department of Physiology and Pharmacology, Wake Forest University, Winston-Salem, NC, USA \\ ${ }_{2}^{2}$ Oregon National Primate Research Center, Oregon Health and Sciences University, Beaverton, OR, USA \\ ${ }^{3}$ Department of Psychiatry and Behavioral Sciences, Wake Forest University, Winston-Salem, NC, USA
}

\section{Edited by:}

Lara Ray, University of California, USA

Reviewed by:

Raj Sevak, University of California, USA

Shaolin Wang, University of Virginia, USA

\section{*Correspondence:}

Scott E. Hemby, Medical Center Boulevard, Wake Forest University School of Medicine, Winston-Salem, NC 27157, USA.

e-mail:shemby@wfubmc.edu
Functional impairment of the orbital and medial prefrontal cortex underlies deficits in executive control that characterize addictive disorders, including alcohol addiction. Previous studies indicate that alcohol alters glutamate neurotransmission and one substrate of these effects may be through the reconfiguration of the subunits constituting ionotropic glutamate receptor (iGluR) complexes. Glutamatergic transmission is integral to cortico-cortical and cortico-subcortical communication and alcohol-induced changes in the abundance of the receptor subunits and/or their splice variants may result in critical functional impairments of prefrontal cortex in alcohol dependence. To this end, the effects of chronic ethanol self-administration on glutamate receptor ionotropic AMPA (GRIA) subunit variant and kainate (GRIK) subunit mRNA expression were studied in the orbitofrontal cortex (OFC), dorsolateral prefrontal cortex (DLPFC), and anterior cingulate cortex (ACC) of male cynomolgus monkeys. In DLPFC, total AMPA splice variant expression and total kainate receptor subunit expression were significantly decreased in alcohol drinking monkeys. Expression levels of GRIA3 flip and flop and GRIA4 flop mRNAs in this region were positively correlated with daily ethanol intake and blood ethanol concentrations (BEC) averaged over the 6 months prior to necropsy. In OFC, AMPA subunit splice variant expression was reduced in the alcohol treated group. GRIA2 flop mRNA levels in this region were positively correlated with daily ethanol intake and BEC averaged over the 6 months prior to necropsy. Results from these studies provide further evidence of transcriptional regulation of iGluR subunits in the primate brain following chronic alcohol self-administration. Additional studies examining the cellular localization of such effects in the framework of primate prefrontal cortical circuitry are warranted.

\section{Keywords: ethanol, AMPA, kainate, messenger RNA, prefrontal cortex, qPCR, primate}

\section{INTRODUCTION}

Alcohol abuse is characterized in part by short-term and longterm biochemical alterations in brain regions that affect subsequent intake, withdrawal, relapse, and cognition. The majority of research conducted in this area has focused on alterations in midbrain and forebrain regions within the mesolimbic dopamine system that mediate hypothetical motivational processes (Di Chiara and Imperato, 1988; Brodie et al., 1990). More recently, the prefrontal cortex has received increasing attention in addiction processes because alcoholics show deficits in decision-making like those of individuals with damage to specific prefrontal fields. In particular, damage to either the dorsolateral prefrontal cortex (DLPFC) or orbitofrontal cortex (OFC), produce impairments that suggest that these fields may be contributing substrates in alcoholism (Bechara, 2003; Pears et al., 2003). Results from functional imaging studies support the idea of alcohol-induced prefrontal cortical alterations. Functional magnetic resonance imaging (fMRI) has revealed increased activation of the medial frontal, orbitofrontal, and cingulate cortices that is correlated with self-reported alcohol-induced craving (Wrase et al., 2002; Myrick et al., 2004). Furthermore, a priming dose of alcohol sensitizes cueinduced responses in these regions (Bragulat et al., 2008). Such findings support the hypothesis that prefrontal cortical dysregulation is involved in the mediation of craving and compulsive alcohol intake (Volkow and Fowler, 2000).

Despite evidence linking excessive alcohol intake to dysfunction of specific prefrontal cortical regions, studies exploring biochemical correlates in prefrontal cortex have been limited to human post-mortem tissue analysis (Mitsuyama et al., 1998; Mayfield et al., 2002; Alexander-Kaufman et al., 2006). The use of a nonhuman primate model of ethanol self-administration enables a clinically relevant characterization of chronic alcohol intake in a well-controlled laboratory setting without confounding variables inherent in human post-mortem studies (e.g., reliable intake measures, lifestyle characteristics, multidrug histories, etc.). The model exhibits important aspects of human alcohol consumption, including an alcoholic drinking phenotype confirmed with blood ethanol concentrations (BEC; Grant et al., 2008). Moreover, 
non-human primate cortex exhibits significant anatomical and biochemical similarities with human cortex that facilitate the translation of findings to humans (Preuss, 2001). Previous studies using this model have found marked alterations in GABA-A and NMDA receptor subunit mRNA expression in the DLPFC and OFC but not in anterior cingulate cortex (ACC; Hemby et al., 2006; Acosta et al., 2010), suggesting region specific GABA/glutamate imbalances in the primate prefrontal cortex.

$\alpha$-Amino-3-hydroxy-5-methyl-4-isoxazolepropionic acid (AMPA) and kainate receptors comprise two additional families of glutamate-gated ion channel receptors (Ozawa et al., 1998). AMPA and kainate receptors are critical for fast synaptic transmission and have important roles in neuronal development and long- and short-term neuroplasticity (Pinheiro and Mulle, 2006). AMPA and kainate receptors are tetrameric assemblies of subunits composed of GluR1-4 and GluR5-7, KA1 and KA2 subunits, respectively (Keinanen et al., 1990; Rosenmund et al., 1998). AMPA receptors are responsible for the majority of fast excitatory synaptic transmission in the brain and their activation is necessary for depolarization and release the tonic $\mathrm{Mg}^{2+}$ blockade of NMDA receptors, thereby enabling NMDA receptor activation. AMPA receptor subunits undergo post-transcriptional processing including alternative splicing to yield flip and flop variants that mediate receptor desensitization (Quirk et al., 2004), the rate of receptor re-sensitization (Partin et al., 1994) and of channel closing (Pei et al., 2007), thereby enabling greater diversity in channel kinetics and pharmacological profiles for these receptors. Kainate receptors are closely related to AMPA receptors but constitute a separate family of ionotropic glutamate receptor (iGluR) and have unique roles on synaptic transmission depending on receptor subunit composition and whether they are located pre- or post-synaptically (Huettner, 2003; Plested and Mayer, 2007).

The intoxicating and reinforcing effects of ethanol are mediated in part by the effects on AMPA and kainate receptors (Valenzuela and Cardoso, 1999; Backstrom and Hyytia, 2004; Sanchis-Segura et al., 2006; Jones et al., 2008; Palachick et al., 2008; Stuber et al., 2008). Previous studies have demonstrated that acute ethanol decreases AMPA and kainate receptor-mediated currents in a variety of limbic brain regions (Weiner et al., 1999; Crowder et al., 2002; Carta et al., 2003; Moykkynen et al., 2003; Stuber et al., 2008). Chronic intermittent ethanol administration, by contrast, has been shown to increase AMPA and kainate receptor-mediated transmission in the basolateral amygdala (Lack et al., 2007, 2009) and increase GluR3 flip variant mRNA expression in the hippocampus of rats (Bruckner et al., 1997).

These studies and others have shed considerable light on the involvement of AMPA/kainate receptors in alcohol abuse as well as the effects of alcohol on the expression and function of these receptor classes; however, few studies have attempted to examine the effects of chronic ethanol administration in primate prefrontal cortical regions. Studies using human alcoholic post-mortem tissue provide typically contain several confounding variables (e.g., comorbid psychiatric conditions, periodicity and chronicity of consumption, polysubstance use and abuse) that have a direct impact on multiple biochemical measures. Non-human primate models more closely approximate the neuroanatomical and biochemical milieu of the human brain. The primate cerebral cortex is highly elaborated in comparison to rodents especially in prefrontal regions that are emerging as important substrates for addictive disorders. In the rat, the prefrontal cortex is composed only of a set of agranular fields (e.g., dorsal and ventral anterior cingulate, prelimbic and infralimbic fields) and lacks the intricate expansion found in primates. The primate brain contains agranular fields as well but adds dysgranular and granular fields that are not found in rodents (Carmichael and Price, 1994; Ongur and Price, 2000). The use of non-human primate models enables a clear and clinically relevant characterization of behavioral and biochemical changes associated with chronic alcohol use in a well-controlled laboratory setting. To further investigate the potential contribution of AMPA and kainate receptor subunit expression in the prefrontal cortical dysfunction characteristic of alcoholism, we examined AMPA and kainate receptor subunit mRNA expression, including AMPA flip/flop variants in the DLPFC, OFC, and ACC of cynomolgus monkeys following chronic ethanol self-administration.

\section{EXPERIMENTAL PROCEDURES}

\section{SUBJECTS AND ETHANOL SELF-ADMINISTRATION}

Ten adult male cynomolgus monkeys (Macaca fascicularis; 5.56.5 years at beginning of experiment) were subjects for the present experiments ( $n=6$ ethanol group, $n=4$ control group). The drinking model and the animals behavior has been extensively analyzed elsewhere (Vivian et al., 2001; Grant et al., 2008). Six adult male cynomolgus monkeys were quarantined for 2 months and then transferred to the laboratory primate housing room and assigned a cage within a quadrant rack as described previously. Attached to one wall of each monkey's home cage was an operant panel that allowed access to all fluid and food requirements. Monkeys were trained to operate the drinking panel in daily 60min sessions and then induced to drink water and later ethanol $(4 \% \mathrm{w} / \mathrm{v}$ in water). Following 120 days of induction, scheduled pellet delivery was discontinued. For 6 months, ethanol and water were available ad libitum and food was available in meals during daily 16-h sessions. Following that, the monkeys underwent ethanol abstinence for 12 months. After the abstinence period, the monkeys were again allowed access to $4 \%$ ethanol, water, or food from the panel for $22 \mathrm{~h} / \mathrm{d}$ for a range of 558-595 consecutive days (approximately 18 months). During the ad libitum period monkeys were allowed to self-administer $4 \%$ (w/v) ethanol daily, with the volume and rate of alcohol consumed determined solely by the monkey. Once the animals are given free access to ethanol, the onset of daily 22-h sessions are signaled by the illumination of amber stimulus lights above both drinking spouts. Both $4 \%(\mathrm{w} / \mathrm{v})$ alcohol and water were available at all times during the daily 22-h sessions. In addition, a "meal structure" was imposed so monkeys were required to eat the daily allotment of food in no less than three "meals," with at least $2 \mathrm{~h}$ between each meal.

Experimentally naïve control subjects $(n=4)$ were the same as those described previously (Hemby et al., 2006; Acosta et al., 2010). Following 2 months of quarantine, monkeys were placed on the same diet as the ethanol-drinking animals (Vivian et al., 2001) and had very similar daily routines as the ethanol-drinking animals. 
Control individuals remained in the laboratory for 6 months prior to euthanasia.

Blood samples $(20 \mu \mathrm{l})$ for the analysis of BEC were taken from the saphenous vein every fifth day from every monkey just before the lights turning off in the room and approximately $7 \mathrm{~h}$ following the onset of the session. Blood samples were sealed in air-tight vials containing $500 \mu \mathrm{l}$ of distilled water and $20 \mu \mathrm{l}$ of isopropanol (10\%; internal standard) and stored at $-4^{\circ} \mathrm{C}$ until assay using a gas chromatograph (Hewlett-Packard 5890 Series II, Avondale, PA, USA) equipped with a headspace autosampler, flame ionization detector, and a Hewlett-Packard 3392A integrator. All behavioral studies were conducted in the laboratory of Dr. Grant at Wake Forest University. The care of the animals and euthanasia procedures in this study were performed according to the National Institutes for Health Guide for the Care and Use of Laboratory Animals, and were approved by the Institutional Animal Care and Use Committee of Wake Forest University.

\section{NECROPSY}

Following euthanasia and removal of the brain, the prefrontal cortex was dissected from the rest of the brain and the OFC (Area 13), ACC (Area 24), and DLPFC (Area 46) were dissected as described previously (Hemby et al., 2006). The OFC dissection included the medial and lateral aspects of the medial orbital sulcus located rostral to the rostral end of the corpus callosum, and therefore included Areas 13a and 13m (Carmichael and Price, 1994). The ACC was dissected from the rostral pole of the corpus callosum and included tissue from the cingulate gyrus up to but not including the lower bank of the cingulate sulcus, and therefore contained fields 24a and 24b. The DLPFC (Area 46) was dissected from the banks of the principle sulcus midway along its length.

\section{RNA ISOLATION AND cDNA SYNTHESIS}

Total RNA was isolated using Trizol (Sigma-Aldrich, St. Louis, MO, USA) followed by chloroform extraction/isopropanol precipitation and stored at $-80^{\circ} \mathrm{C}$. Two microgram of total RNA from each sample, as well as a pool of total RNA combined from the 10 cynomolgus monkeys, was reverse transcribed using random primers and SuperScript III kits (Invitrogen, Carlsbad, CA, USA) according to the manufacturer's protocol. Resulting cDNA product was diluted 1:100 with RNAse-free water for samples, and cDNA from the pooled samples was serially diluted in twofold dilutions from 1:20 to 1:640 for use as standards.

\section{REAL-TIME QUANTITATIVE PCR}

Custom Taqman assays were designed for the eight AMPA subunit splice variants in collaboration with Applied Biosystems (Foster City, CA, USA). All assays used FAM reporter dye and NFQ quencher and were designed such that the Taqman probe spanned the exon-exon junction (or included exon) that is specific to the splice variant being measured. Sequence information for these assays is listed in Table 1. Standard Taqman assays were purchased for measurement of specific kainate receptor subunits and synaptic proteins (GRIA1: Hs00181348_m1; GRIA2: Hs00181331_m1; GRIA3: Hs00241485_m1; GRIA4: Hs00168163_m1; GRIK1: Hs00168165_m1;GRIK2:Hs00222637_m1;GRIK3:Hs00168182_ m1, GRIK4: Hs00205979_m1; GRIK5: Hs00361590_m1; PICK1: Hs00202661_m1; GRIP: Hs00294733_m1; Applied Biosystems, Foster City, CA, USA).

Using a 384 well format with the ABI Prism 7900HTS realtime detector, $0.5 \mu \mathrm{l}$ aliquots of Taqman Expression Assay $(20 \times)$, $5.0 \mu \mathrm{l} 2 \times$ Absolute QPCR ROX PCR Mastermix (Abgene), and $4.5 \mu \mathrm{l}$ diluted $\mathrm{cDNA}$ (either sample or pooled standard) were mixed together and pipetted into single wells of the PCR plate. For no template controls (NTC) for each gene tested, water was added in lieu of cDNA. Each sample, including NTC was run in triplicate. Thermocycling conditions: (1) one cycle $2 \mathrm{~min}$ at $50^{\circ} \mathrm{C}$, (2) one cycle $15 \mathrm{~min}$ at $95^{\circ} \mathrm{C}$, and (3) 40 cycles $15 \mathrm{~s}$ at $95^{\circ} \mathrm{C}$ and $1 \mathrm{~min}$ at $60^{\circ} \mathrm{C}$. Fluorescence was measured during the $60^{\circ} \mathrm{C}$ step for each cycle. Reactions were quantified by the standard curve method using SDS2.1 software generating a mean quantity value (Qty mean) for each sample from the triplicates of that sample for each gene of interest. Endogenous controls were selected from a set of seven candidate reference transcripts: $\beta$-actin (ACTB: Hs99999903_m1), ribosomal protein 18S (18S: Hs99999901_m1), TATA box binding protein (TBP: Hs99999910_m1), hypoxanthine phosphoribosyltransferase 1 (HPRT1), peptidylprolylisomerase A (cyclophilin A) (PPIA: Hs99999904_m1), $\beta$-glucuronidase (GUSB), and phosphoglycerate kinase 1 (PGK1:Hs99999906_m1) using geNorm software. geNorm is a collection of VBA macros for Microsoft Excel which allows the determination of the most stable reference genes from a given test panel of genes. By computing the average pairwise variation $(\mathrm{V})$ for each control gene paired with all other tested control genes, geNorm calculates the gene expression stability measure (M). This allows for the selection of the most stably expressed control genes in a given sample set, minimizing any bias in the data as a result of normalization. The gene expression

Table 1 | Sequence information for custom designed AMPA splice variant TaqMan assays.

\begin{tabular}{llll}
\hline Gene & Probe sequence & Forward primer & Reverse primer \\
\hline GluR1 flip & CACTGAGTTTCAAAACCG & CTCCTGGAGTCCACCATGAATG & CGGAGTCCTTGCTTCCACATT \\
GluR1 flop & CCCCTGCTCGTTTAGTTT & TGGAGTCCACCATGAATGAGTACA & ACCTCCCCGCTGC \\
GluR2 flip & ACCCCAGTAAATCTTG & TGGATTCCAAAGGCTATGGCATC & CCTTGGCTCCACATTCACCTT \\
GluR2 flop & CCTCGCAGTACTAAAAC & AACCTGGATTCCAAAGGCTATGG & CCGCTGCCGCACTCT \\
GluR3 flip & CAGTGAACAAGGCATCTTA & AGGCTATGGTGTGGCAACC & GGAGTCCTTGGCTCCACATTC \\
GluR3 flop & AACTGAATGAGCAAGGCCT & TGGATTCCAAAGGCTATGGTGTG & CCGCTGCCGCACTC \\
GluR4 flip & CAGTGAGGCAGGCGTC & AGCAGCGAAACCATGTGA & AGAGTCTTTGGGTCCACATTCAC \\
GluR4 flop & AAGGCCTCTTGGACAAAT & GAGCAGCGAAAGCATGTG & 145 \\
& & AGTCACCTCCCCCGCT
\end{tabular}


normalization factor is calculated based on the geometric mean of a user-defined number of reference genes (Vandesompele et al., 2002). Three candidate genes, PGK1, TBP, HPRT, were selected to serve as endogenous controls. Data for each gene of interest was expressed as Qty mean for the gene of interest/geometric mean of Qty mean values for the selected endogenous control genes. Normalized values are expressed as percent control.

\section{STATISTICAL ANALYSIS}

Levels of gene expression were calculated using SDS 2.1 software (Applied Biosystems, Foster City, CA, USA) to interpolate the $C_{\mathrm{t}}$ values for each well onto a standard curve generated from the $C_{\mathrm{t}}$ values of a dilution series of standards. These quantity values were then averaged across triplicates after removal of outliers and expressed relative to the quantity value for the mean of the endogenous control genes measured in the same sample on the same plate. This relative value (gene of interest Qty mean/endogenous control Qty mean) was used for subsequent statistical analysis. Experiments determining relative gene expression for each candidate gene were run independently. For each gene, two-way analysis of variance was employed with Group (Ethanol and Control) and Subunit (per receptor class) as the Main factors and mRNA abundance as the dependent variable. All subunits for a receptor class were analyzed for each brain regions separately. Bonferroni's test was used for post hoc analyses. In addition, Pearson Correlation analysis was conducted for each transcript with average daily ethanol intake for the final 6 months prior to necropsy, total intake over the 18-month period and the BEC for the final 6 months prior to necropsy. Null hypotheses were rejected when $P<0.05$.

\section{RESULTS}

Individual drinking patterns of the six monkeys included in this study have been reported previously (Vivian et al., 2001; Hemby et al., 2006). The average daily ethanol intake for 6 months of self-administration prior to necropsy ranged from 1.4 to $3.7 \mathrm{~g} / \mathrm{kg}$ ethanol and the average BEC ranged from 62 to $188 \mathrm{~g} / \mathrm{kg}$. Mean daily ethanol intake, total intake, and BEC are provided in Table 2. Estimations of these intakes in terms of human drink-equivalents is roughly $0.25 \mathrm{~g} / \mathrm{kg}$ per drink, or a range of 6-15 drinks/day during the last 6 months of self-administration prior to the brain being harvested. These levels of drinking are considered heavy in terms of human ethanol consumption (guidelines posted at www.niaaa.nih.gov).

Table 2 | Ethanol Consumption for monkeys used in this study.

\begin{tabular}{llll}
\hline Subject & $\begin{array}{l}\text { Daily intake } \\
(\mathbf{g} / \mathbf{k g})\end{array}$ & $\begin{array}{l}\text { Total intake } \\
\mathbf{( g / k g )}\end{array}$ & $\begin{array}{l}\text { Blood ethanol } \\
\text { concentration }(\boldsymbol{n})\end{array}$ \\
\hline 5404 & $3.33 \pm 0.24$ & 2289.8 & $188 \pm 17(33)$ \\
5497 & $1.76 \pm 0.10$ & 1670.8 & $105 \pm 11(33)$ \\
6101 & $1.85 \pm 0.012$ & 1524.2 & $100 \pm 9(28)$ \\
6304 & $1.17 \pm 0.13$ & 897.8 & $63 \pm 13(30)$ \\
6305 & $1.49 \pm 0.08$ & 1184.5 & $62 \pm 10(30)$ \\
6306 & $2.70 \pm 0.17$ & 2757.7 & $173 \pm 10(35)$ \\
\hline
\end{tabular}

Daily intake values and blood ethanol concentrations represent mean \pm SEM.

\section{DORSOLATERAL PREFRONTAL CORTEX}

In the DLPFC, we observed a significant Group $\times$ Subunit interaction for the GRIA subunits $[F(3,39)=3.576, P=0.025]$, with a significant decrease in GRIA4 $(P=0.002$; Figure 1A). For the AMPA splice variants, we observed a significant Main Effect of Group $[F(1,79)=6.891, P=0.011]$ and significant Group $\times$ Subunit interaction $[F(7,79)=3.101, P=0.007]$, where post hoc analyses revealed a decrease in the GRIA4 flip variant $(P<0.001)$ in the alcohol group (Figure 1B). GRIA3, GRIA3 flip and flop, and GRIA4 flop mRNAs were positively correlated with average daily intake and average BEC for the 6 months prior to necropsy $(P<0.05)$. GRIA2 flop mRNA was positively correlated with BEC but not average intake (Table 3 ).

Kainate receptor subunit mRNAs were significantly decreased in the ethanol group $[F(1,49)=5.330 ; P=0.026]$; however, there was no significant Group $\times$ Subunit interaction $[F(4,49)=0.785$; $P=0.542]$ (Figure 2A). There were no significant differences in PICK1 or GRIP1 between the alcohol and control groups in

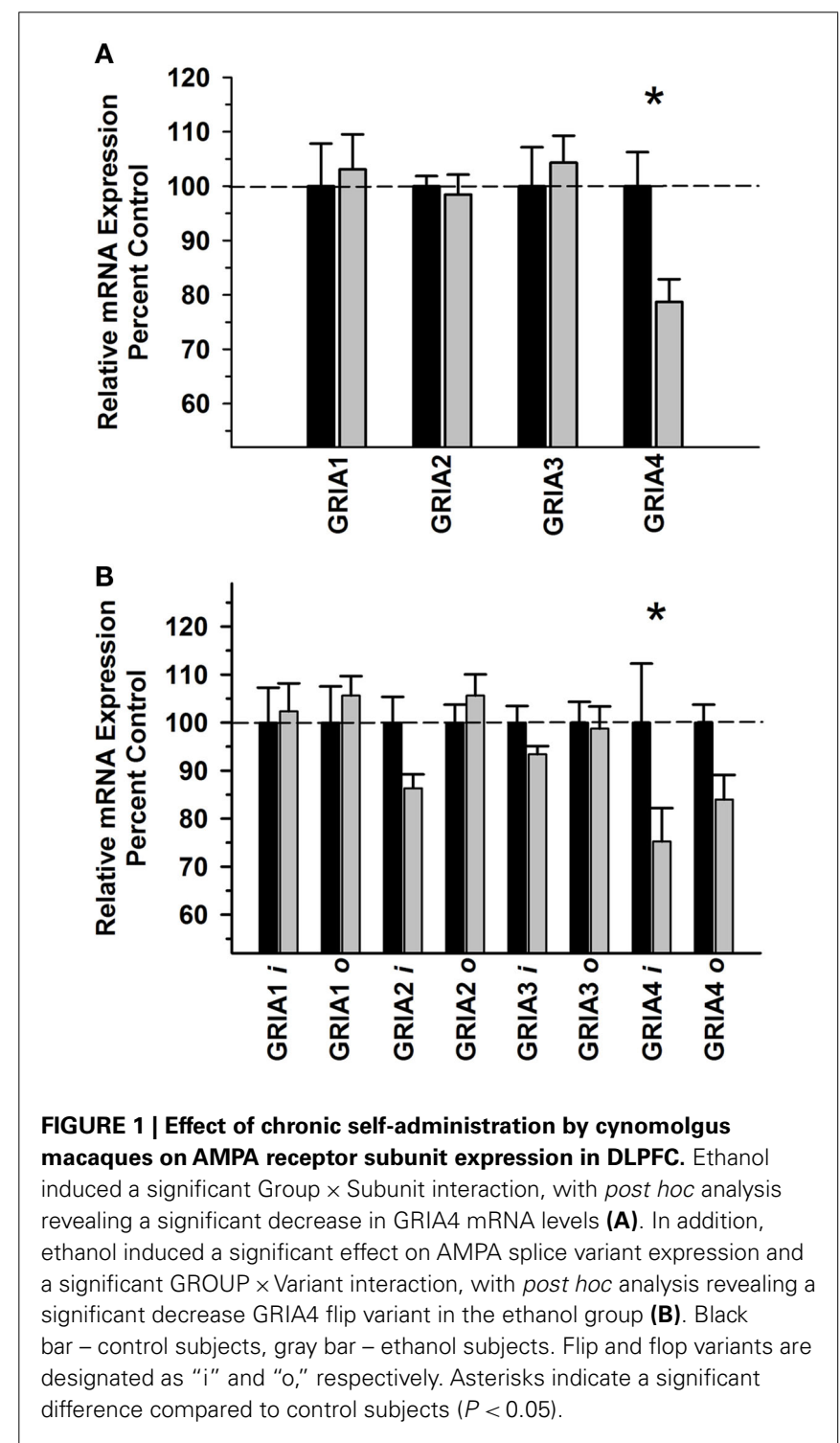




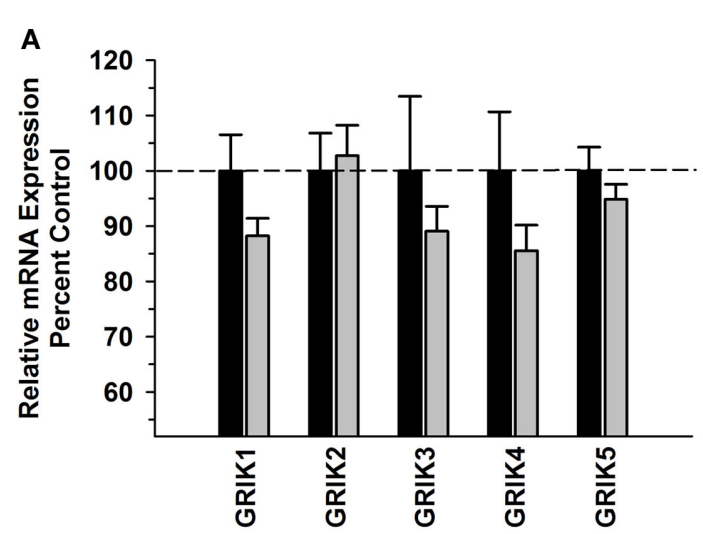

B

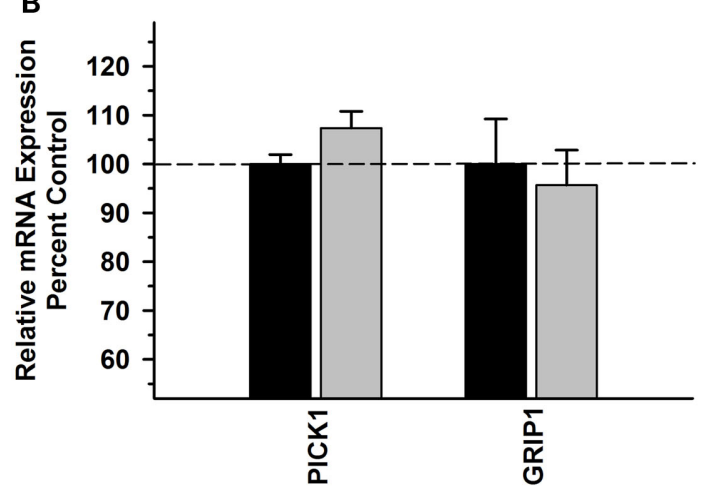

FIGURE 2 | Effect of chronic self-administration on kainate receptor subunits, PICK1 and GRIP1 mRNA expression in the DLPFC. Ethanol induced a significant decrease in kainate receptor subunit mRNA in the region; however there was no significant Group $\times$ Subunit interaction (A). No significant differences were observed between the groups for PICK1 and GRIP1 (B). Black bar - control subjects, gray bar - ethanol subjects.

this region (Figure 2B) and no significant correlations between the kainate receptor subunits, PICK1 or GRIP mRNA levels and average daily intake and average BEC for the 6 months prior to necropsy (Table 3).

\section{ORBITOFRONTAL CORTEX}

In the OFC, there was no significant difference in GRIA receptor subunit mRNAs between the Groups $[F(1,39)=0.000257$, $P=0.987]$ and no significant Group $\times$ Subunit interaction $[F(3,39)=0.261, \quad P=0.853] \quad$ (Figure 3A). GRIA variant expression was significantly different between the groups $[F(1,70)=19.504 ; P<0.001]$, but there was no significant interaction observed $[F(7,79)=0.319 ; P=0.943]$ (Figure 3B). GRIA 2 flop mRNA levels were significantly correlated with both average daily intake and average BEC for the 6 months prior to necropsy (Table 3).

No significant difference was observed in kainate receptor subunit mRNA expression between the Groups $[F(1,49)=0.637$, $P=0.430]$ and there was no significant Group $\times$ Subunit interaction $[F(4,49)=1.840 ; P=0.140]$ (Figure 4A). Moreover, there were no significant differences in PICK1 or GRIP1 between the alcohol and control groups in this region (Figure 4B) and no significant correlations between the kainate receptor subunits, PICK1 or GRIP mRNA levels and average daily intake and average BEC for the 6 months prior to necropsy (Table 3 ).

\section{ANTERIOR CINGULATE CORTEX}

In contrast to the other prefrontal regions, there were no significant Main Effects or interactions for GRIA subunits $([F(1,39)=0.0289$, $P=0.866] ;[F(3,39)=0.541, P=0.657]$ or GRIA splice variants $([F(1,79)=0.836, P=0.364][F(7,79)=0.659, P=0.706]$; Figures 5A,B, respectively). No significant difference was observed in kainate receptor subunit mRNA expression either between Groups $[F(1,49)=0.185, P=0.669]$ or in Group $\times$ Subunit interaction $[F(4,49)=0.260 ; P=0.902]$ (Figure 6A). In addition, there were no significant differences in PICK1 or GRIP1 between the alcohol and control groups (Figure 6B). No significant correlations were observed between AMPA subunits, AMPA splice variant, kainate subunits, PICK1 or GRIP mRNA levels and average daily intake and average BEC for the 6 months prior to necropsy (Table 3).

\section{DISCUSSION}

The current findings indicate that chronic ethanol selfadministration decreased the expression of mRNAs that encode specific AMPA and kainate receptor subunits. Significant decreases were observed in AMPA subunit splice variant expression and kainate subunit expression in DLPFC. Moreover, GRIA3 flip and flop variants as well as the GRIA4 flop variant expression was positively correlated with BECs as well as ethanol intake 6 months prior necropsy. Total AMPA splice variant expression was decreased in the OFC with GRIA2 flop mRNA expression levels positively correlated with BECs as well as ethanol intake 6 months prior necropsy. No changes in kainate receptor subunit expression or AMPArelated synaptic proteins, PICK1 and GRIP1, were observed in any of the three brain regions analyzed. These data support and expand the results of studies in humans (Gass and Olive, 2008; Ridge et al., 2008; Schumann et al., 2008; Ridge and Dodd, 2009) and nonhuman primates (Hemby et al., 2006; Acosta et al., 2010). The present results along with previous studies implicating GABAergic dysregulation suggests a glutamate/GABA imbalance in DLPFC and OFC that would likely disrupt information processing in prefrontal microcircuits and corresponding cortical fields known to be involved in cognitive functions altered by alcohol abuse and addiction (Figure 7). Future studies will be required to determine if alterations in iGluR and GABA-A subunit mRNA are reflected in receptor composition and how such alterations might affect the physiology of the neurons on which they are located.

AMPA receptors contribute to fast neurotransmission while also mediating $\mathrm{Ca}^{2+}$ flux. The functional diversity of AMPA receptors subunits can be alternatively spliced to yield flip and flop variants with flip variants confer slower desensitization times to the receptor in which they are present, resulting in longer channel open times and increased neuronal excitability (Mosbacher et al., 1994; Koike et al., 2000). Studies have found these splice variants to be expressed in different ratios depending on development, drug administration, and disease state (Monyer et al., 1991; Eastwood et al., 1997). Kainate receptors exert smaller excitatory post-synaptic potentials than AMPA receptors, yet appear to 
Table 3 | Correlational analysis of gene expression with average daily intake and average blood ethanol concentrations for the 6 months prior to necropsy.

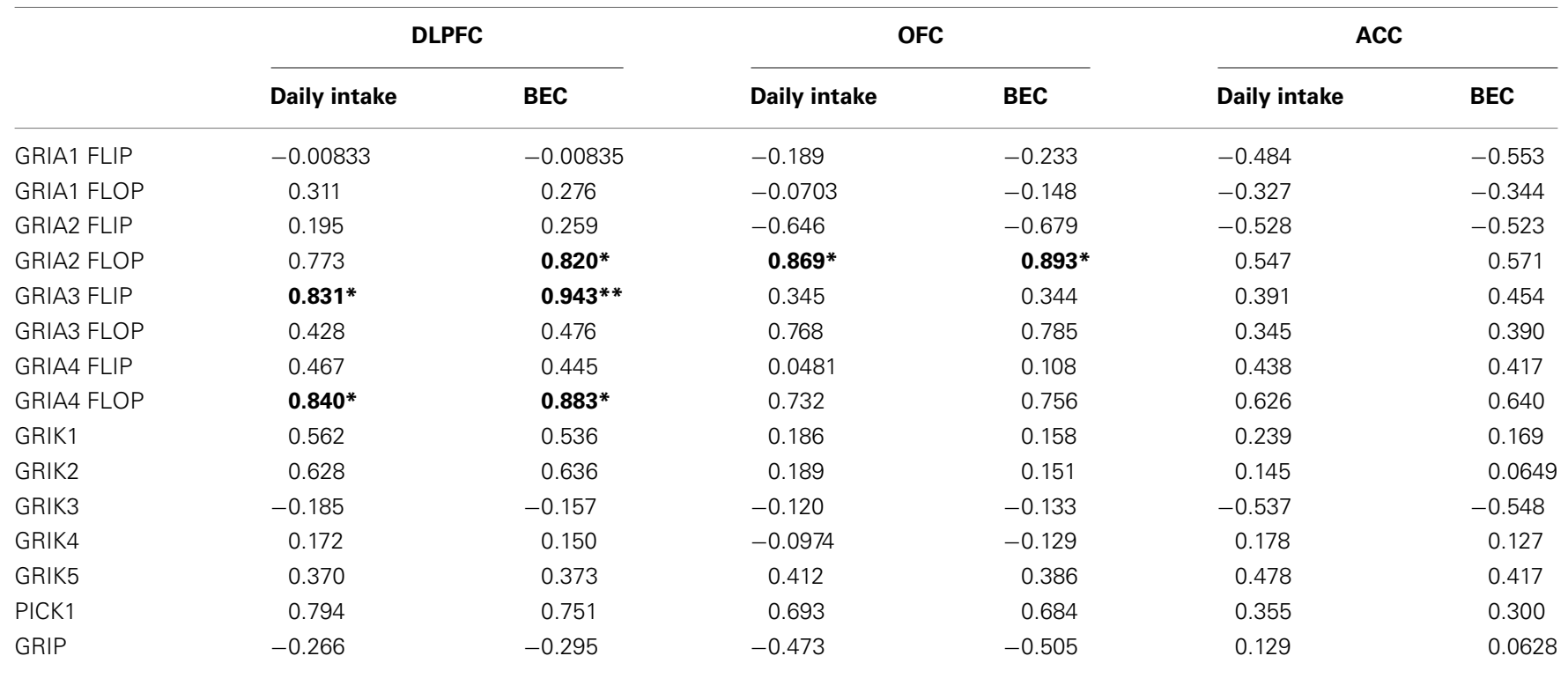

Values expressed are Pearson correlation coefficients $\left(r^{2}\right)$ for the six male monkeys that consumed alcohol in the present study. ${ }^{*} P<0.05 ;{ }^{* *} P<0.01$. Bold values highlight statistical significance of Pearson correlations.
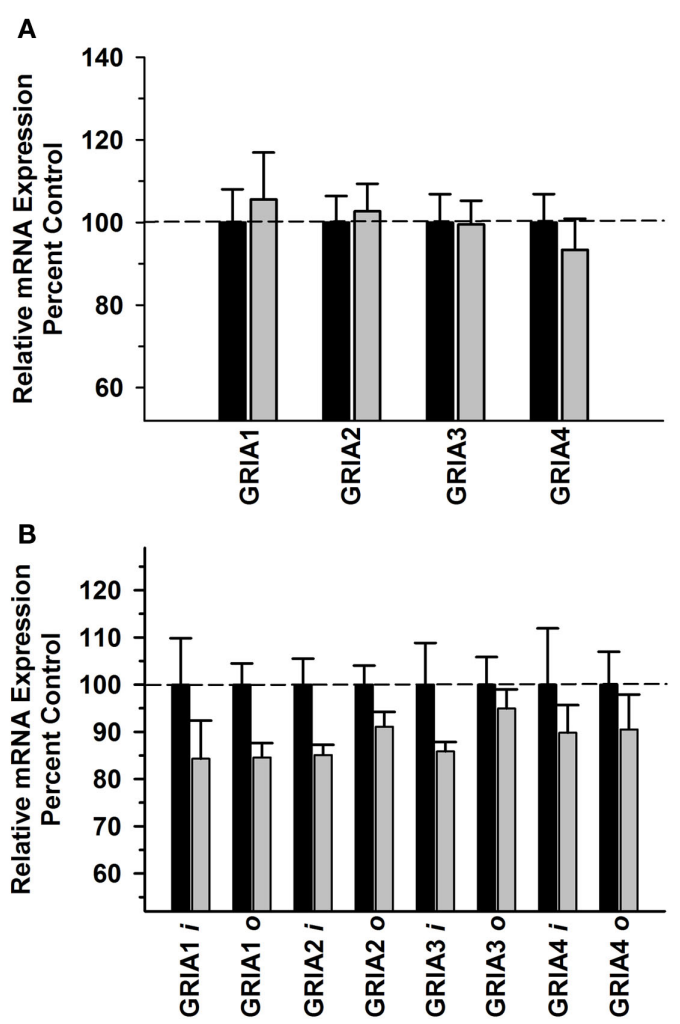

FIGURE 3 | Effect of chronic self-administration by cynomolgus macaques on AMPA receptor subunit expression in OFC. Ethanol self-administration did not affect AMPA receptor subunit mRNA expression in this region (A), but did alter AMPA subunit splice variant expression (B). Black bar - control subjects, gray bar - ethanol subjects.
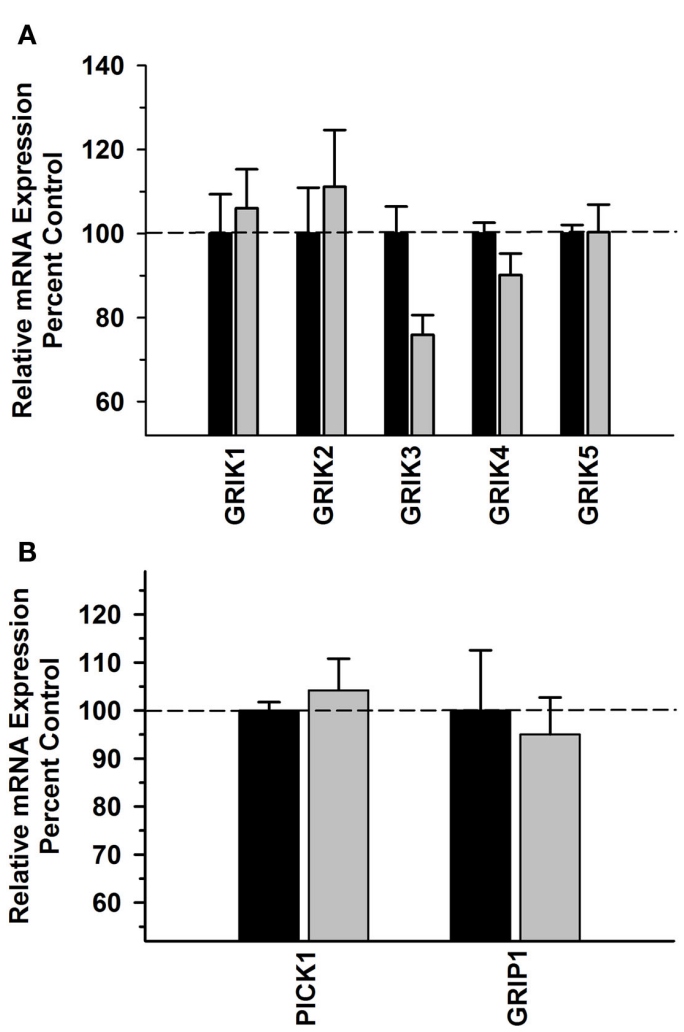

FIGURE 4 | Effect of chronic self-administration on kainate receptor subunits (A), PICK1 and GRIP1 (B) mRNA expression in the OFC. No significant differences were observed between the groups for any of the transcripts evaluated. Black bar - control subjects, gray bar - ethanol subjects. 

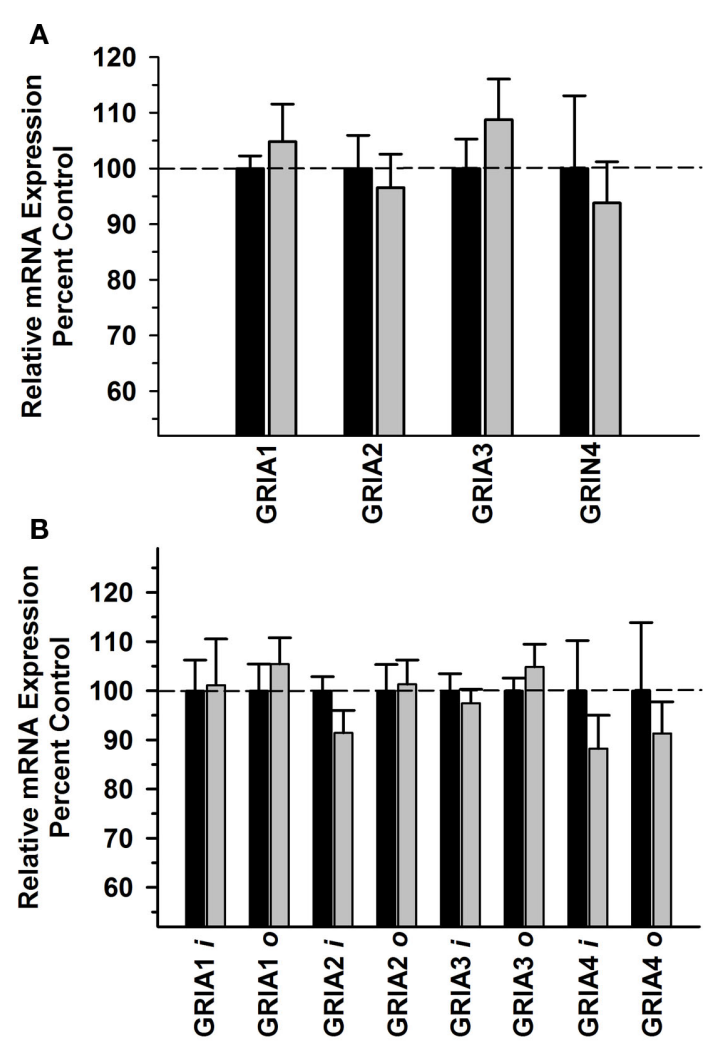

FIGURE 5 | Effect of chronic self-administration by cynomolgus macaques on AMPA subunit expression in ACC. Ethanol did not alter the expression of AMPA receptor subunits $(\mathbf{A})$ or AMPA splice variants $(\mathbf{B})$ in this region. Black bar - control subjects, gray bar - ethanol subjects.

contribute a significant prolonged depolarization under repetitive neuronal firing (Pinheiro and Mulle, 2006). Pre-synaptically localized kainate receptors modulate both excitatory and inhibitory neurotransmitter release. The mechanisms of kainate receptor regulation during alcoholism and other forms of synaptic plasticity is far less understood than AMPA or NMDA regulation. Previous studies have indicated that the intoxicating and reinforcing effects of ethanol are mediated in part by the effects on AMPA and kainate receptors (Valenzuela and Cardoso, 1999; Backstrom and Hyytia, 2004; Sanchis-Segura et al., 2006; Jones et al., 2008; Stuber et al., 2008). For example, acute ethanol decreases AMPA and kainate receptor-mediated currents in a variety of limbic brain regions (Weiner et al., 1999; Crowder et al., 2002; Carta et al., 2003; Moykkynen et al., 2003; Stuber et al., 2008). By contrast, chronic intermittent ethanol administration has been shown to increase AMPA and kainate receptor-mediated transmission in the basolateral amygdala (Lack et al., 2007, 2009) and increase GluR3 flip variant mRNA expression in the hippocampus of rats (Bruckner et al., 1997). Currently, there are no published data correlating the effects of chronic ethanol consumption on AMPA or kainate receptor subunit expression or receptor binding in primate prefrontal cortex.

Rodent studies reveal that extracellular glutamate levels are elevated in the nucleus accumbens in mice with a history of high

alcohol consumption (Szumlinski et al., 2007) as well as in rats in the basolateral amygdala during cue-induced reinstatement of alcohol intravenous self-administration (Gass et al., 2011). Moreover, bouts of moderate ethanol consumption increase basal glutamate levels in the CA3 region of the hippocampus (Chefer et al., 2011). An integral role of iGluR transmission is further implicated by several demonstrations that modulators at these receptors affect alcohol intake and reinstatement. Ethanol selfadministration is reduced by competitive and non-competitive NDMA receptor antagonists (Rassnick et al., 1992; Bienkowski et al., 1999; Holter et al., 2000; Malpass et al., 2010) and competitive AMPA/kainate receptor antagonists (Stephens and Brown, 1999). Cue-induced reinstatement of ethanol maintained responding is reduced by lamotrigine, a glutamate release inhibitor (Vengeliene et al., 2007), competitive NMDA receptor antagonists (Backstrom and Hyytia, 2004; Bachteler et al., 2005), the NMDA receptor modulator acamprosate (Bachteler et al., 2005) as well as competitive AMPA/kainate antagonists (Backstrom and Hyytia, 2004; Sanchis-Segura et al., 2006), including topiramate (Knapp et al., 2007; Lynch et al., 2011).

Previous studies in humans demonstrate clearly the potential role of iGluR modulators in the regulation of alcohol 


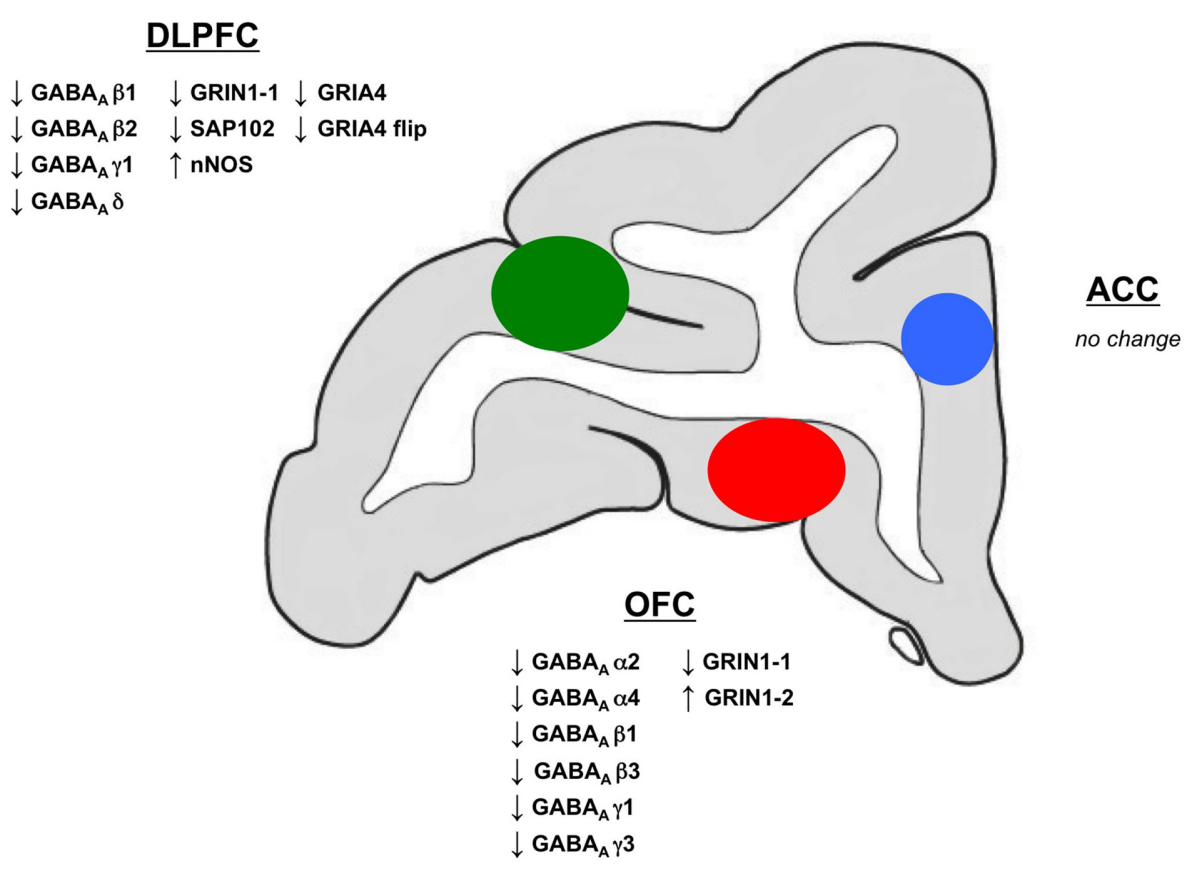

FIGURE 7 | Schematic map summarizing GABA-A and iGluR subunit changes in DLPFC, ACC and OFC. Coronal section illustrating the general locations of tissue dissected for the DLPFC (green), ACC (blue) and OFC (red) used in this study. Changes in mRNA expression of GABAA, NR1 and AMPA subunits as well as synaptic proteins are indicated beside the respective regions. intake, craving, withdrawal symptoms and other outcome measures (Krupitsky et al., 2007; Johnson, 2010). For example, topiramate reduces the percentage of heavy drinking days and improve self-reported outcomes in alcohol dependent individuals (Johnson et al., 2007). While topiramate exhibits multiple mechanisms of action, including sodium channel opening, AMAP/kainate and GABA-A receptor modulation, the effect on alcohol intake likely involves antagonism of kainate receptors, specifically, GluR5. Merging the effects of chronic alcohol intake on AMPA and kainate mRNA expression with documented or potential efficacy of pharmacological compounds is tenuous at best. Nevertheless, the present data do not provide insight on the involvement of prefrontal cortical regions in the observed preclinical or clinical efficacy of topiramate or lamotrigine. The possibility exists that blockade of glutamate release or GluR5 antagonism in other regions might mediate the effects of these compounds.

The current findings of altered AMPA dysregulation in the DLPFC offer a potential neurobiological substrate of the DLPFC associated cognitive dysfunction in alcoholics (Bechara, 2003; Pears et al., 2003). Furthermore, the results offer a biological basis into the potential use of compounds that selectively target AMPA receptors. For example, LY404187 or the enantiomer LY451646, allosteric AMPA receptor modulators (AMPAkines), preferentially affect GluR2 and GluR4 and potentiate the flip variants more so than the flop variants of these receptors. LY404187 selectively increased the probability of PFC pyramidal neuron firing in response to stimulation from hippocampal afferents (Baumbarger et al., 2001) and enhance cognitive performance in rodent models (Staubli et al., 1994) and memory encoding in humans (Ingvar et al., 1997). In the present scenario, reductions in GluR4 flip expression in the DLPFC could be overcome by amplifying glutamate transmission using compounds such as LY404187/LY451646. The possibility of a connection between decreased GluR4 flip expression and altered cognitive function as a function of chronic alcohol intake remains to be determined. Given the evidence of improved cognitive performance by allosteric AMPA modulators, it is reasonable to suggest that members of this family of compounds may prove beneficial in the treatment of cognitive dysfunction in alcoholics.

Previous studies in humans suggest the prefrontal cortex, especially fields located on the orbital and medial surfaces, play an important role in addiction and are rendered dysfunctional as a consequence of long-term alcohol consumption. Human alcoholics exhibit alterations in DLPFC cerebral blood flow and impairments in executive function during early abstinence (Zinn et al., 2004). Furthermore, alcohol craving has been associated also with increased functional activity of the DLPFC (George et al., 2001; Wrase et al., 2002; Tapert et al., 2004; Olbrich et al., 2006) and OFC (Wrase et al., 2002; Tapert et al., 2003; Myrick et al., 2004). OFC has been implicated in impulsivity (Jentsch and Taylor, 1999), response inhibition (Elliott et al., 2000a,b; Goldstein et al., 2001; Liddle et al., 2001), and the attribution as well as evaluation of stimulus salience (Thorpe et al., 1983; Tremblay and Schultz, 1999; Hikosaka and Watanabe, 2000; Goldstein and Volkow, 2002), all of which are impaired in alcohol and other addictions. Characterization of the biochemical basis of the 
functional and anatomical alterations in primate prefrontal cortex and associated behavioral deficits induced by chronic ethanol consumption are needed to better understand the neuropathological consequences of alcoholism as well as to develop and/or improve existing pharmacotherapies to reduce or alleviate such deficits.

There is no question that mRNA levels may not correlate precisely with protein abundance, an important next step is to include functional assessments of AMPA and kainate receptors in these cortical fields. Currently available antibodies enable the detection of AMPA subunits but can not differentiate flip and flop splice variants. In the current study, assessment of protein levels via Western blot analysis was not possible due to the small amount of dissected tissue and previous studies utilizing aliquots of the same tissue to examine GABA-A and iGluR subunits and synaptic proteins.

Accumulating evidence suggests that changes in DLPFC and OFCiGluR and GABA-A receptors may underlie the functional deficits resulting from chronic alcohol abuse (Bechara and Damasio, 2002; Goldstein and Volkow, 2002; Bechara, 2003). Examination of the effects of ethanol on cognitive function in the monkey as well as levels of receptor subunit expression, the

\section{REFERENCES}

Acosta, G., Hasenkamp, W., Daunais, J. B., Friedman, D. P., Grant, K. A., and Hemby, S. E. (2010). Ethanol self-administration modulation of NMDA receptor subunit and related synaptic protein mRNA expression in prefrontal cortical fields in cynomolgus monkeys. Brain Res. 1318, 144-154.

Alexander-Kaufman, K., James, G., Sheedy, D., Harper, C., and Matsumoto, I. (2006). Differential protein expression in the prefrontal white matter of human alcoholics: a proteomics study. Mol. Psychiatry $11,56-65$.

Bachteler, D., Economidou, D., Danysz, W., Ciccocioppo, R., and Spanagel, R. (2005). The effects of acamprosate and neramexane on cueinduced reinstatement of ethanolseeking behavior in rat. Neuropsychopharmacology 30, 1104-1110.

Backstrom, P., and Hyytia, P. (2004). Ionotropic glutamate receptor antagonists modulate cue-induced reinstatement of ethanol-seeking behavior. Alcohol. Clin. Exp. Res. 28, 558-565.

Baumbarger, P. J., Muhlhauser, M., Zhai, J., Yang, C. R., and Nisenbaum, E. S. (2001). Positive modulation of alpha-amino-3-hydroxy5-methyl-4-isoxazole propionic acid (AMPA) receptors in prefrontal cortical pyramidal neurons by a novel allosteric potentiator. J. Pharmacol. Exp. Ther. 298, 86-102.

Bechara, A. (2003). Risky business: emotion, decision-making, and addiction. J. Gambl. Stud. 19, 23-51.
Bechara, A., and Damasio, H. (2002). Decision-making and addiction (part I): impaired activation of somatic states in substance dependent individuals when pondering decisions with negative future consequences. Neuropsychologia 40, 1675-1689.

Bienkowski, P., Koros, E., Kostowski, W., and Danysz, W. (1999). Effects of Nmethyl-D-aspartate receptor antagonists on reinforced and nonreinforced responding for ethanol in rats. Alcohol 18, 131-137.

Bragulat, V., Dzemidzic, M., Talavage, T., Davidson, D., O'Connor, S. J., and Kareken, D. A. (2008). Alcohol sensitizes cerebral responses to the odors of alcoholic drinks: an fMRI study. Alcohol. Clin. Exp. Res. 32, 1124-1134.

Brodie, M. S., Shefner, S. A., and Dunwiddie, T. V. (1990). Ethanol increases the firing rate of dopamine neurons of the rat ventral tegmental area in vitro. Brain Res. 508, 65-69.

Bruckner, M. K., Rossner, S., and Arendt, T. (1997). Differential changes in the expression of AMPA receptors genes in rat brain after chronic exposure to ethanol: an in situ hybridization study. J. Hirnforsch. 38, 369-376.

Carmichael, S. T., and Price, J. L. (1994). Architectonic subdivision of the orbital and medial prefrontal cortex in the macaque monkey. $J$. Comp. Neurol. 346, 366-402.

Carta, M., Ariwodola, O. J., Weiner, J. L., and Valenzuela, C. F. (2003). Alcohol potently inhibits the kainate receptor-dependent excitatory drive of hippocampal interneurons.

class of neurons that are primarily affected, and the expression of related trafficking and anchoring proteins and their genes within these prefrontal regions will be fundamental to ascertaining the molecular pathology of prefrontal dysregulation in alcoholism.

\section{ACKNOWLEDGMENTS}

The study was supported by NIAAA grants P20 AA011997, U01 AA013510 (Kathleen A. Grant), and Wake Forest University Health Sciences (Scott E. Hemby).

\section{AUTHOR CONTRIBUTIONS}

Kathleen A. Grant and Scott E. Hemby were responsible for the study concept and design. Glen Acosta and Scott E. Hemby performed data analysis and interpreted molecular data. Scott E. Hemby drafted the manuscript and Glen Acosta, David P. Freidman, and Kathleen A. Grant provided critical revision of the manuscript for important intellectual content. All authors critically reviewed content and approved the final version for submission.

Proc. Natl. Acad. Sci. U.S.A. 100, 6813-6818.

Chefer, V., Meis, J., Wang, G., Kuzmin, A., Bakalkin, G., and Shippenberg, T. (2011). Repeated exposure to moderate doses of ethanol augments hippocampal glutamate neurotransmission by increasing release. Addict. Biol. 16, 229-237.

Crowder, T. L., Ariwodola, O. J., and Weiner, J. L. (2002). Ethanol antagonizes kainate receptor-mediated inhibition of evoked GABA(A) inhibitory postsynaptic currents in the rat hippocampal CA1 region. $J$. Pharmacol. Exp. Ther. 303, 937-944.

Di Chiara, G., and Imperato, A. (1988). Drugs abused by humans preferentially increase synaptic dopamine concentrations in the mesolimbic system of freely moving rats. Proc. Natl. Acad. Sci. U.S.A. 85, 5274-5278.

Eastwood, S. L., Burnet, P. W., and Harrison, P. J. (1997). GluR2 glutamate receptor subunit flip and flop isoforms are decreased in the hippocampal formation in schizophrenia: a reverse transcriptasepolymerase chain reaction (RTPCR) study. Brain Res. Mol. Brain Res. 44, 92-98.

Elliott, R., Dolan, R. J., and Frith, C. D. (2000a). Dissociable functions in the medial and lateral orbitofrontal cortex: evidence from human neuroimaging studies. Cereb. Cortex 10 , 308-317.

Elliott, R., Friston, K. J., and Dolan, R. J. (2000b). Dissociable neural responses in human reward systems. J. Neurosci. 20, 6159-6165.
Gass, J. T., and Olive, M. F. (2008). Glutamatergic substrates of drug addiction and alcoholism. Biochem. Pharmacol. 75, 218-265.

Gass, J. T., Sinclair, C. M., Cleva, R. M., Widholm, J. J., and Olive, M. F. (2011). Alcohol-seeking behavior is associated with increased glutamate transmission in basolateral amygdala and nucleus accumbens as measured by glutamate-oxidasecoated biosensors. Addict. Biol. 16, 215-228.

George, M. S., Anton, R. F., Bloomer, C., Teneback, C., Drobes, D. J. Lorberbaum, J. P., Nahas, Z., and Vincent, D. J. (2001). Activation of prefrontal cortex and anterior thalamus in alcoholic subjects on exposure to alcohol-specific cues. Arch. Gen. Psychiatry 58, 345-352.

Goldstein, R. Z., and Volkow, N. D. (2002). Drug addiction and its underlying neurobiological basis: neuroimaging evidence for the involvement of the frontal cortex. Am. J. Psychiatry 159, 1642-1652.

Goldstein, R. Z., Volkow, N. D., Wang, G. J., Fowler, J. S., and Rajaram, S. (2001). Addiction changes orbitofrontal gyrus function: involvement in response inhibition. Neuroreport 12, 2595-2599.

Grant, K. A., Leng, X., Green, H. L., Szeliga, K. T., Rogers, L. S., and Gonzales, S. W. (2008). Drinking typography established by scheduled induction predicts chronic heavy drinking in a monkey model of ethanol self-administration. Alcohol. Clin. Exp. Res. 32, 1824-1838. 
Hemby, S. E., O’Connor, J, A., Acosta, G., Floyd, D., Anderson, N., McCool, B. A., Friedman, D., and Grant, K. A. (2006). Ethanol-induced regulation of GABA-A subunit mRNAs in prefrontal fields of cynomolgus monkeys. Alcohol. Clin. Exp. Res. 30, 1978-1985.

Hikosaka, K., and Watanabe, M. (2000). Delay activity of orbital and lateral prefrontal neurons of the monkey varying with different rewards. Cereb. Cortex 10, 263-271.

Holter, S. M., Danysz, W., and Spanagel, R. (2000). Novel uncompetitive N-methyl-D-aspartate (NMDA)receptor antagonist MRZ 2/579 suppresses ethanol intake in longterm ethanol-experienced rats and generalizes to ethanol cue in drug discrimination procedure. $J$. Pharmacol. Exp. Ther. 292, 545-552.

Huettner, J. E. (2003). Kainate receptors and synaptic transmission. Prog. Neurobiol. 70, 387-407.

Ingvar, M., Ambros-Ingerson, J., Davis, M., Granger, R., Kessler, M., Rogers, G. A., Schehr, R. S., and Lynch, G. (1997). Enhancement by an ampakine of memory encoding in humans. Exp. Neurol. 146, 553-559.

Jentsch, J. D., and Taylor, J. R. (1999). Impulsivity resulting from frontostriatal dysfunction in drug abuse: implications for the control of behavior by reward-related stimuli. Psychopharmacology (Berl.) 146, 373-390.

Johnson, B. A. (2010). Medication treatment of different types of alcoholism. Am. J. Psychiatry 167, 630-639.

Johnson, B. A., Rosenthal, N., Capece, J. A., Wiegand, F., Mao, L., Beyers, K., McKay, A., Ait-Daoud, N., Anton, R. F., Ciraulo, D. A., Kranzler, H. R., Mann, K., O'Malley, S. S., and Swift, R. M. (2007). Topiramate for treating alcohol dependence: a randomized controlled trial. JAMA 298, 1641-1651.

Jones, N., Messenger, M. J., O’Neill, M. J., Oldershaw, A., Gilmour, G., Simmons, R. M., Iyengar, S., Libri, V., Tricklebank, M., and Williams, S. C. (2008). AMPA receptor potentiation can prevent ethanol-induced intoxication. Neuropsychopharmacology 33, 1713-1723.

Keinanen, K., Wisden, W., Sommer, B., Werner, P., Herb, A., Verdoorn, T. A., Sakmann, B., and Seeburg, P. H. (1990). A family of AMPAselective glutamate receptors. Science 249, 556-560.

Knapp, C. M., Mercado, M., Markley, T. L., Crosby, S., Ciraulo, D. A., and Kornetsky, C. (2007). Zonisamide decreases ethanol intake in rats and mice. Pharmacol. Biochem. Behav. 87, 65-72.

Koike, M., Tsukada, S., Tsuzuki, K., Kijima, H., and Ozawa, S. (2000). Regulation of kinetic properties of GluR2 AMPA receptor channels by alternative splicing. J. Neurosci. 20, 2166-2174.

Krupitsky, E. M., Rudenko, A. A., Burakov, A. M., Slavina, T. Y., Grinenko, A. A., Pittman, B., Gueorguieva, R., Petrakis, I. L., Zvartau, E. E., and Krystal, J. H. (2007). Antiglutamatergic strategies for ethanol detoxification: comparison with placebo and diazepam. Alcohol. Clin. Exp. Res. 31, 604-611.

Lack, A. K., Christian, D. T., Diaz, M. R., and McCool, B. A. (2009). Chronic ethanol and withdrawal effects on kainate receptor-mediated excitatory neurotransmission in the rat basolateral amygdala. Alcohol 43 , 25-33.

Lack, A. K., Diaz, M. R., Chappell, A., DuBois, D. W., and McCool, B. A. (2007). Chronic ethanol and withdrawal differentially modulate preand postsynaptic function at glutamatergic synapses in rat basolateral amygdala. J. Neurophysiol. 98, 3185-3196.

Liddle, P. F., Kiehl, K. A., and Smith, A. M. (2001). Event-related fMRI study of response inhibition. Hum. Brain Mapp. 12, 100-109.

Lynch, W. J., Bond, C., Breslin, F. J., and Johnson, B. A. (2011). Severity of drinking as a predictor of efficacy of the combination of ondansetron and topiramate in rat models of ethanol consumption and relapse. Psychopharmacology (Berl.) 217, 3-12.

Malpass, G. E., Williams, H. L., and McMillen, B. A. (2010). Effects of the non-competitive NMDA receptor antagonist memantine on the volitional consumption of ethanol by alcohol-preferring rats. Basic Clin. Pharmacol. Toxicol. 106, 435-444.

Martin, R. F., and Bowden, D. M. (1996). A stereotaxic template atlas of the macaque brain for digital imaging and quantitative neuroanatomy. Neuroimage 4, 119-150.

Mayfield, R. D., Lewohl, J. M., Dodd, P. R., Herlihy, A., Liu, J., and Harris, R. A. (2002). Patterns of gene expression are altered in the frontal and motor cortices of human alcoholics. J. Neurochem. 81, 802-813.

Mitsuyama, H., Little, K. Y., Sieghart, W., Devaud, L. L., and Morrow, A. L. (1998). GABA(A) receptor alpha1, alpha4, and beta3 subunit mRNA and protein expression in the frontal cortex of human alcoholics. Alcohol. Clin. Exp. Res. 22, 815-822.

Monyer, H., Seeburg, P. H., and Wisden, W. (1991). Glutamate-operated channels: developmentally early and mature forms arise by alternative splicing. Neuron 6, 799-810.

Mosbacher, J., Schoepfer, R., Monyer, H., Burnashev, N., Seeburg, P. H., and Ruppersberg, J. P. (1994). A molecular determinant for submillisecond desensitization in glutamate receptors. Science 266, 1059-1062.

Moykkynen, T., Korpi, E. R., and Lovinger, D. M. (2003). Ethanol inhibits alpha-amino-3-hydyroxy5-methyl-4-isoxazolepropionic acid (AMPA) receptor function in central nervous system neurons by stabilizing desensitization. J. Pharmacol. Exp. Ther. 306, 546-555.

Myrick, H., Anton, R. F., Li, X., Henderson, S., Drobes, D., Voronin, K., and George, M. S. (2004). Differential brain activity in alcoholics and social drinkers to alcohol cues: relationship to craving. Neuropsychopharmacology 29, 393-402.

Olbrich, H. M., Valerius, G., Paris, C., Hagenbuch, F., Ebert, D., and Juengling, F. D. (2006). Brain activation during craving for alcohol measured by positron emission tomography. Aust. N. Z. J. Psychiatry 40, 171-178.

Ongur, D., and Price, J. L. (2000). The organization of networks within the orbital and medial prefrontal cortex of rats, monkeys and humans. Cereb. Cortex 10, 206-219.

Ozawa, S., Kamiya, H., and Tsuzuki, K. (1998). Glutamate receptors in the mammalian central nervous system. Prog. Neurobiol. 54, 581-618.

Palachick, B., Chen, Y. C., Enoch, A. J., Karlsson, R. M., Mishina, M., and Holmes, A. (2008). Role of major NMDA or AMPA receptor subunits in MK-801 potentiation of ethanol intoxication. Alcohol. Clin. Exp. Res. 32, 1479-1492.

Partin, K. M., Patneau, D. K., and Mayer, M. L. (1994). Cyclothiazide differentially modulates desensitization of alpha-amino-3-hydroxy5-methyl-4-isoxazolepropionic acid receptor splice variants. Mol. Pharmacol. 46, 129-138.

Pears, A., Parkinson, J. A., Hopewell, L., Everitt, B. J., and Roberts, A. C. (2003). Lesions of the orbitofrontal but not medial prefrontal cortex disrupt conditioned reinforcement in primates. J. Neurosci. 23, 11189-11201.

Pei, W., Huang, Z., and Niu, L. (2007). GluR3 flip and flop: differences in channel opening kinetics. Biochemistry 46, 2027-2036.

Pinheiro, P., and Mulle, C. (2006). Kainate receptors. Cell Tissue Res. 326, 457-482.

Plested, A. J., and Mayer, M. L. (2007). Structure and mechanism of kainate receptor modulation by anions. Neuron 53, 829-841.

Preuss, T. M. (2001). “The discovery of cerebral diversity: an unwelcome scientific revolution," in Evolutionary Anatomy of the Primate Cerebral Cortex, eds D. Falk and K. Gibson (Cambridge: Cambridge University Press), 138-164.

Quirk, J. C., Siuda, E. R., and Nisenbaum, E. S. (2004). Molecular determinants responsible for differences in desensitization kinetics of AMPA receptor splice variants. J. Neurosci 24, 11416-11420.

Rassnick, S., Pulvirenti, L., and Koob, G. F. (1992). Oral ethanol selfadministration in rats is reduced by the administration of dopamine and glutamate receptor antagonists into the nucleus accumbens. Psychopharmacology 109, 92-98.

Ridge, J. P., and Dodd, P. R. (2009). Cortical NMDA receptor expression in human chronic alcoholism: influence of the TaqIA allele of ANKK1. Neurochem. Res. 34, 1775-1782.

Ridge, J. P., Ho, A. M., Innes, D. J., and Dodd, P. R. (2008). The expression of NMDA receptor subunit mRNA in human chronic alcoholics. Ann. N. Y. Acad. Sci. 1139, 10-19.

Rosenmund, C., Stern-Bach, Y., and Stevens, C. F. (1998). The tetrameric structure of a glutamate receptor channel. Science 280, 1596-1599.

Sanchis-Segura, C., Borchardt, T., Vengeliene, V., Zghoul, T., Bachteler, D., Gass, P., Sprengel, R., and Spanagel, R. (2006). Involvement of the AMPA receptor GluR-C subunit in alcoholseeking behavior and relapse. J. Neurosci. 26, 1231-1238.

Schumann, G., Johann, M., Frank, J., Preuss, U., Dahmen, N., Laucht, M., Rietschel, M., Rujescu, D., Lourdusamy, A., Clarke, T. K., Krause, K., Dyer, A., Depner, M., Wellek, S., Treutlein, J., Szegedi, A., Giegling, I., Cichon, S., Blomeyer, D., Heinz, A., Heath, S., Lathrop, M., Wodarz, N., Soyka, M., Spanagel, R., and Mann, K. (2008). Systematic analysis of glutamatergic neurotransmission genes in alcohol dependence and adolescent risky drinking behavior. Arch. Gen. Psychiatry 65, 826-838.

Staubli, U., Rogers, G., and Lynch, G. (1994). Facilitation of glutamate receptors enhances memory. Proc. Natl. Acad. Sci. U.S.A. 91, 777-781. 
Stephens, D. N., and Brown, G. (1999). Disruption of operant oral self-administration of ethanol, sucrose, and saccharin by the AMPA/kainate antagonist, NBQX, but not the AMPA antagonist, GYKI 52466. Alcohol. Clin. Exp. Res. 23, 1914-1920.

Stuber, G. D., Hopf, F. W., Hahn, J., Cho, S. L., Guillory, A., and Bonci, A. (2008). Voluntary ethanol intake enhances excitatory synaptic strength in the ventral tegmental area. Alcohol. Clin. Exp. Res. 32, 1714-1720.

Szumlinski, K. K., Diab, M. E., Friedman, R., Henze, L. M., Lominac, K. D., and Bowers, M. S. (2007). Accumbens neurochemical adaptations produced by binge-like alcohol consumption. Psychopharmacology 190, 415-431.

Tapert, S. F., Brown, G. G., Baratta, M. V., and Brown, S. A. (2004). fMRI BOLD response to alcohol stimuli in alcohol dependent young women. Addict. Behav. 29, 33-50.

Tapert, S. F., Cheung, E. H., Brown, G. G., Frank, L. R., Paulus, M. P., Schweinsburg, A. D., Meloy, M. J., and Brown, S. A. (2003). Neural response to alcohol stimuli in adolescents with alcohol use disorder. Arch. Gen. Psychiatry 60, 727-735.

Thorpe, S. J., Rolls, E. T., and Maddison, S. (1983). The orbitofrontal cortex: neuronal activity in the behaving monkey. Exp. Brain Res. 49, 93-115.

Tremblay, L., and Schultz, W. (1999). Relative reward preference in primate orbitofrontal cortex. Nature 398, 704-708.

Valenzuela, C. F., and Cardoso, R. A. (1999). Acute effects of ethanol on kainate receptors with different subunit compositions. J. Pharmacol. Exp. Ther. 288, 1199-1206.

Vandesompele, J., De Preter, K., Pattyn, F., Poppe, B., Van Roy, N., De Paepe, A., and Speleman, F. (2002). Accurate normalization of real-time quantitative RT-PCR data by geometric averaging of multiple internal control genes. Genome Biol. 3, RESEARCH0034.

Vengeliene, V., Heidbreder, C. A., and Spanagel, R. (2007). The effects of lamotrigine on alcohol seeking and relapse. Neuropharmacology 53, 951-957.

Vivian, J. A., Green, H. L., Young, J. E., Majerksy, L. S., Thomas, B.
W., Shively, C. A., Tobin, J. R., Nader, M. A., and Grant, K. A. (2001). Induction and maintenance of ethanol self-administration in cynomolgus monkeys (Macaca fascicularis): long-term characterization of sex and individual differences. Alcohol. Clin. Exp. Res. 25, 1087-1097.

Volkow, N. D., and Fowler, J. S. (2000). Addiction, a disease of compulsion and drive: involvement of the orbitofrontal cortex. Cereb. Cortex 10, 318-325.

Weiner, J. L., Dunwiddie, T. V., and Valenzuela, C. F. (1999). Ethanol inhibition of synaptically evoked kainate responses in rat hippocampal CA3 pyramidal neurons. Mol. Pharmacol. 56, 85-90.

Wrase, J., Grusser, S. M., Klein, S., Diener, C., Hermann, D., Flor H., Mann, K., Braus, D. F., and Heinz, A. (2002). Development of alcohol-associated cues and cue-induced brain activation in alcoholics. Eur. Psychiatry 17, 287-291.

Zinn, S., Stein, R., and Swartzwelder, H. S. (2004). Executive functioning early in abstinence from alcohol. Alcohol. Clin. Exp. Res. 28, 1338-1346.

Conflict of Interest Statement: The authors declare that the research was conducted in the absence of any commercial or financial relationships that could be construed as a potential conflict of interest.

Received: 02 September 2011; accepted: 26 November 2011; published online: 03 January 2012.

Citation: Acosta G, Freidman DP, Grant KA and Hemby SE (2012) Alternative splicing of AMPA subunits in prefrontal cortical fields of cynomolgus monkeys following chronic ethanol selfadministration. Front. Psychiatry 2:72. doi: 10.3389/fpsyt.2011.00072

This article was submitted to Frontiers in Addictive Disorders, a specialty of Frontiers in Psychiatry.

Copyright (C) 2012 Acosta, Freidman, Grant and Hemby. This is an open-access article distributed under the terms of the Creative Commons Attribution Non Commercial License, which permits noncommercial use, distribution, and reproduction in other forums, provided the original authors and source are credited. 